\title{
Gene methylation profiles of normal mucosa, and benign and malignant colorectal tumors identify early onset markers Terje Ahlquist ${ }^{1,2}$, Guro E Lind ${ }^{1,2}$, Vera L Costa1,3, Gunn I Meling ${ }^{4,5,9}$, Morten Vatn ${ }^{5,6}$, Geir S Hoff7, Torleiv O Rognum4,5, Rolf I Skotheim ${ }^{1,2}$, Espen Thiis-Evensen ${ }^{6}$ and Ragnhild A Lothe*1,2,8
}

\begin{abstract}
Address: ${ }^{1}$ Department of Cancer Prevention, Institute for Cancer Research, Norwegian Radium Hospital, Rikshospitalet University Hospital, Oslo Norway, ${ }^{2}$ Centre for Cancer Biomedicine, University of Oslo, Norway, ${ }^{3}$ Department of Genetics, Portuguese Oncology Institute, Porto, Portugal, ${ }^{4}$ Institute of Forensic Medicine, Rikshospitalet Medical Centre, University of Oslo, Oslo, Norway, ${ }^{5}$ Faculty of Medicine, University of Oslo, Norway, ${ }^{6}$ Medical Department, Rikshospitalet Medical Centre, Oslo, Norway, ${ }^{7}$ Department of Medicine, Division of Gastroenterology, Telemark Hospital, Skien, Norway, ${ }^{8}$ Department of Molecular Biosciences, University of Oslo, Oslo, Norway and ${ }^{9}$ Surgical Department, Faculty Division Akershus University Hospital, University of Oslo, Oslo, Norway

Email: Terje Ahlquist - terje.c.ahlquist@rr-research.no; Guro E Lind - guro.elisabeth.lind@rr-research.no; Vera L Costa - veralmcosta@gmail.com; Gunn I Meling - gi@meling.net; Morten Vatn - morten.vatn@rikshospitalet.no; Geir S Hoff - geir.hoff@sthf.no; Torleiv O Rognum - t.o.rognum@medisin.uio.no; Rolf I Skotheim - Rolf.I.Skotheim@rr-research.no; Espen Thiis-Evensen - espen.thiis-evensen@rikshospitalet.no; Ragnhild A Lothe* - rlothe@rr-research.no

* Corresponding author
\end{abstract}

Published: 31 December 2008

Molecular Cancer 2008, 7:94 doi:10.1/86/1476-4598-7-94
Received: 17 December 2008

Accepted: 31 December 2008

This article is available from: http://www.molecular-cancer.com/content/7/1/94

(c) 2008 Ahlquist et al; licensee BioMed Central Ltd.

This is an Open Access article distributed under the terms of the Creative Commons Attribution License (http://creativecommons.org/licenses/by/2.0), which permits unrestricted use, distribution, and reproduction in any medium, provided the original work is properly cited.

\begin{abstract}
Background: Multiple epigenetic and genetic changes have been reported in colorectal tumors, but few of these have clinical impact. This study aims to pinpoint epigenetic markers that can discriminate between non-malignant and malignant tissue from the large bowel, i.e. markers with diagnostic potential.

The methylation status of eleven genes (ADAMTSI, CDKN2A, CRABPI, HOXA9, MAL, MGMT, MLHI, $N R 3 C I$, PTEN, RUNX3, and SCGB3AI) was determined in 154 tissue samples including normal mucosa, adenomas, and carcinomas of the colorectum. The gene-specific and widespread methylation status among the carcinomas was related to patient gender and age, and microsatellite instability status. Possible CIMP tumors were identified by comparing the methylation profile with microsatellite instability (MSI), BRAF-, KRAS-, and TP53 mutation status.

Results: The mean number of methylated genes per sample was 0.4 in normal colon mucosa from tumorfree individuals, 1.2 in mucosa from cancerous bowels, 2.2 in adenomas, and 3.9 in carcinomas. Widespread methylation was found in both adenomas and carcinomas. The promoters of ADAMTSI, MAL, and MGMT were frequently methylated in benign samples as well as in malignant tumors, independent of microsatellite instability. In contrast, normal mucosa samples taken from bowels without tumor were rarely methylated for the same genes. Hypermethylated CRABPI, MLHI, NR3CI, RUNX3, and SCGB3AI were shown to be identifiers of carcinomas with microsatellite instability. In agreement with the CIMP concept, MSI and mutated BRAF were associated with samples harboring hypermethylation of several target genes.
\end{abstract}

Conclusion: Methylated ADAMTSI, MGMT, and MAL are suitable as markers for early tumor detection. 


\section{Introduction}

Most cases of colorectal cancer (CRC) originate from adenomas. The malignant potential of adenomas increases with size, grade of dysplasia, and degree of villous components, [1] along with the number and order of genetic and epigenetic aberrations.[2] The majority ( $85 \%)$ of the sporadic carcinomas are characterized by chromosomal aberrations, referred to as a chromosomal unstable (CIN) phenotype, whereas the smaller group ( 15\%) typically show microsatellite instability (MSI) caused by defect DNA mismatch repair.[2] Most CIN tumors are microsatellite stable (MSS). A third molecular phenotype characteristic to a subgroup of CRC is the $\mathrm{CpG}$ island methylator phenotype (CIMP).[3] CIMP-positive tumors display methylation of multiple loci, are associated with proximal location in the colon, and are often microsatellite unstable. BRAF mutations are restricted to CIMP positive tumors, which may be sub-classified according to a certain combination of epigenetic and genetic changes. [4]

Here we have compared the time of occurrence and covariation of multiple epigenetic markers in normal colon samples with those of adenomas and carcinomas in order to pinpoint early onset markers for neoplastic transformation.

\section{Materials and methods Tissue samples}

Included in the present study are twenty-one normal colon mucosa samples from twenty deceased, cancer-free individuals, median age 52.5, range 33-86 (called N1 henceforth); 18 normal colon mucosa samples (N2) from 18 CRC patients, median age 70.5, range 24-89 (taken at distance $(>10 \mathrm{~cm})$ from the carcinoma); 63 adenomas, median size $8 \mathrm{~mm}$, range $5-50 \mathrm{~mm}$, from 52 individuals, median age 67 , range $62-72$; and 52 carcinomas from 51 patients, median age 70 , range 33-92. The colon, including the rectum, is divided into proximal and distal sections; the proximal, or right side, spans from coecum to two thirds of the way across transversum; the distal, or left side, comprises the last third of the transversum, sigmoideum, and the rectum. This division originates from the primitive digestive tract, where the right side corresponds from the midgut, while the left side corresponds to the hindgut. The number of proximal versus distal samples in the series is as follows: N1 (10 vs. 11); N2 (7 vs. 11); adenomas (18 vs. 45$)$; and carcinomas (17 vs. 35$)$. The carcinomas included here are from a series evaluated to contain on average $84 \%$ tumor cells.[5] Nine of the N2 samples correspond to nine primary tumors analyzed here. Most of the normal colon samples (26/39) consisted of mucosa only, whereas the remaining ones were taken from the bowel wall. The adenomas were obtained from individuals attending a Norwegian colonoscopy screening program.[6] The carcinomas and the N2 samples are from a prospective series collected from 7 hospitals in the Oslo region of Norway.[5] The N1 samples were autopsy material collected by one of the authors.

The MSI status was determined by use of two mononucleotide markers, BAT25 and BAT26, and a panel of dinucleotide markers. Details regarding the assessment of MSI status are given in Additional file 1.

All samples belong to approved research biobanks and are part of research projects approved according to national guidelines (Biobank; registered at the Norwegian Institute of Public Health. Projects: Regional Ethics Committee and National Data Inspectorate).

\section{DNA methylation analyses}

DNA from all samples was bisulfite modified and subjected to methylation specific polymerase chain reaction (MSP) for each gene.[7,8] Two of the authors independently scored all samples and the methylation status of all positive samples was confirmed by a second, independent round of MSP. If any discrepancies appeared, a third round of analysis was performed. In line with consensus scoring procedures, we considered carcinomas with band intensities as strong as the positive control (++) as methylated [see Additional file 2] for the gene promoter in question, while the benign lesions and normal mucosa were scored as positive also when weakly methylated, i.e. (+).

For detailed MSP protocol, primer sequences, and scoring criteria see Additional file 1. Representative MSP results can be seen in Figure 1.

Eleven genes, ADAMTS1, CDKN2A (encoding p16INK4a),CRABP1, HOXA9, MAL, MGMT, MLH1, NR3C1, PTEN, RUNX3, and SCGB3A1 (encoding HIN-1), were analyzed for promoter methylation by MSP. The methylation status of ADAMTS1, CRABP1, MAL, and NR3C1 for the present series, $[9,10]$ and the methylation status of CDKN2A, MGMT, and MLH1 for the carcinomas [11] have previously been reported.

\section{Quantitative MSP}

Primers and probes for quantitative MSP (qMSP) were designed to specifically amplify fully methylated bisulfiteconverted complementary sequences of the promoter of interest. The primers and probe sequences used for the MGMT [GenBank: NM 002412] are listed in Additional file 3. To normalize for DNA input in each sample, a reference gene (ACTB [12]) was used.

Fluorescence based real-time PCR assays were carried out in a reaction volume of $20 \mu \mathrm{L}$, consisting of $16.6 \mathrm{mM}$ ammonium sulphate; $67 \mathrm{mM}$ trizma preset; $6.7 \mathrm{mM}$ $\mathrm{MgCl}_{2} ; 10 \mathrm{mM}$ mercaptoethanol; 0.1\% DMSO; $200 \mu \mathrm{M}$ 

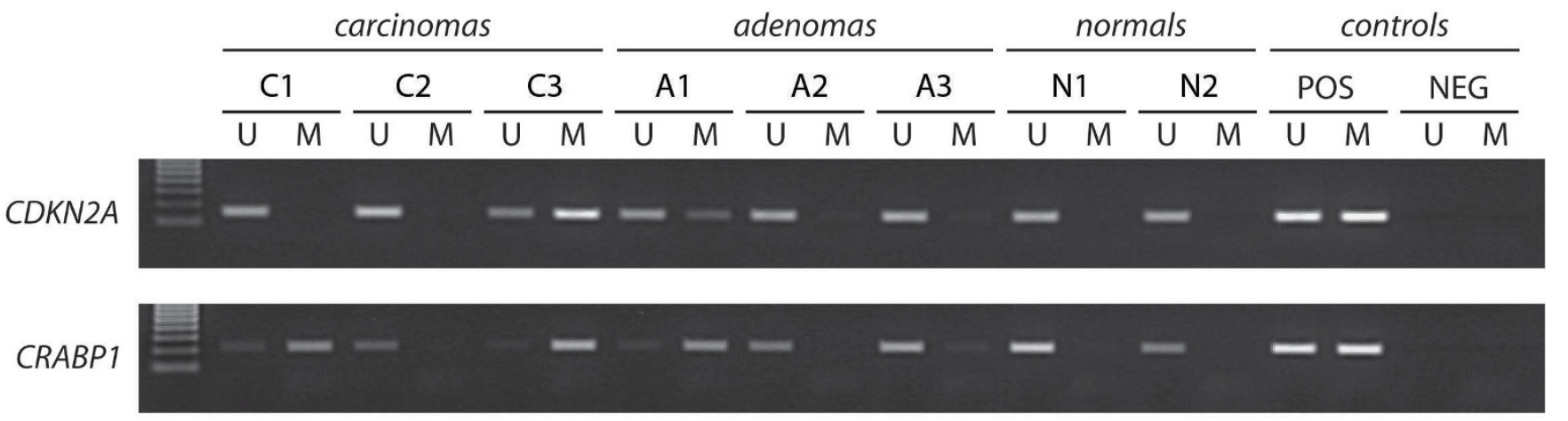

HOXA9

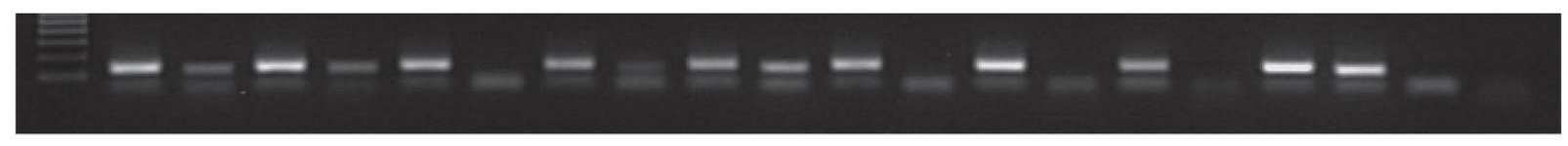

RUNX3

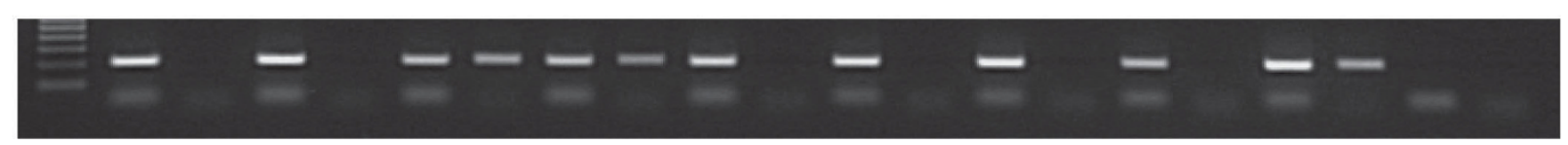

Figure I

Representative methylation results in colorectal tumors and normal mucosa. Results of CDKN2A, CRABPI, HOXA9, and RUNX3 in selected samples are shown. Positive controls (POS): NB, normal blood, for the unmethylated reaction and IVD, in vitro methylated DNA, for methylated reaction. Negative controls: $\mathrm{dH}_{2} \mathrm{O}$. U: unmethylated alleles, M: methylated alleles. The ladder (left lane) is the EZ Load ${ }^{\text {TM }} 100$ bp Molecular Ruler (BioRad, Hercules, CA, USA).

each of dATP, dCTP, dGTP, and dTTP; $600 \mathrm{nM}$ of each primer; $0.4 \mu \mathrm{L}$ of Rox dye; $200 \mathrm{nM}$ of probe; 1 unit of platinum Taq polymerase (Invitrogen, Carlsbad, CA, USA), and $2 \mu \mathrm{l}$ of bisulfite-modified DNA as a template. PCR was performed in separate wells for each primer/probe set and each sample was run in triplicate. Additionally, multiple water blanks were used, and as positive and negative control we used commercial methylated and unmethylated DNA (Millipore, Temecula, CA, USA). A series of dilutions of methylated DNA after bisulfite conversion were used for constructing a standard curve to quantify the amount of fully methylated alleles in each reaction. All amplifications were carried out in 96-well plates on an 7000 Sequence Detection System (Applied Biosystems, Foster City, CA, USA), at $95^{\circ} \mathrm{C}$ for 2 min followed by 45 cycles of $95^{\circ} \mathrm{C}$ for $15 \mathrm{~s}$, and $60^{\circ} \mathrm{C}$ for $1 \mathrm{~min}$.

In order to adjust for the possible various amounts of bisulfite treated DNA input in each PCR, the qMSP levels were normalized against the respective values of the internal reference gene $(A C T B)$. The ratio thus generated constitutes an index of the percentage of input copies of DNA that are fully methylated at the primer- and probe-binding sites. The ratio was multiplied by 100 for easier tabulation (methylation level $=$ target gene/reference gene $\times 100)$.

A given sample was considered positive for promoter hypermethylation when amplification was detected in at least 2 of the triplicates of the respective qMSP analysis.
The qMSP threshold was determined by adjusting the best fit of the slope and R2, using the calibration curve.

\section{Selection criteria for the II gene promoters analyzed in the present study}

Some of the genes analyzed were known to be targeted through promoter methylation in cancer, including colorectal cancer (SCGB3A1, RUNX3, CDKN2A, MLH1, and $M G M T)$. HOXA9 was a potential new methylation target in colorectal cancer. ADAMTS1, CRABP1, MAL, and NR3C1 were identified as novel epigenetically silenced target genes in colorectal cancer by our group. $[9,10,13]$ They were selected to be tested in combination with known methylated genes in a large series of colorectal lesions to check for interdependencies. The methylation status of all included genes was compared in a series of normal mucosa from individuals without cancer with those of normal, benign and malignant tissue from the large bowel of cancer patients. Only two previous studies have compared gene methylation among the same four types of sample groups as investigated here.[14,15] The first only investigated one gene and the latter 10 genes among which only three overlapping the present selected gene list.

\section{Gene mutation status of BRAF, KRAS and TP53}

The present carcinoma series form a part of a series previously studied for genetic changes, including BRAF, KRAS and TP53.[23,24] The specific mutation status of the indi- 
vidual tumors included here can be found in Additional file 4.

\section{Statistics}

The $2 \times 2$ contingency tables were analyzed using Fisher's exact test and $3 \times 2$ tables were analyzed by the Pearson $\chi^{2}$ test. Non-parametric analyses were performed using the Kruskal-Wallis and Mann-Whitney tests. An independent T-test was performed when comparing continuous normally distributed data with two groups. The bivariate correlation analysis was performed with Pearson's correlation. In order to determine age-specific methylation for the genes we used logistic regression analysis. All two-tailed $P$-values were derived from statistical tests using the SPSS15.0 software (SPSS, Chicago, IL, USA), and considered statistically significant at $P \leq 0.05$. The methylation heat-map was generated by average linkage hierarchical clustering and Pearson correlation distance measure, using the SpotFire DecisionSite ${ }^{\varpi} .0$ software.

Seven individuals had multiple polyps in the colon, and to exclude potential bias when analyzing patient data such as sex and age, one polyp from each individual was randomly selected for statistical analyses.

\section{Results \\ MSI status of colorectal tumors}

Two of sixty-three (3\%) polyps displayed MSI. Both were large $(\geq 10 \mathrm{~mm})$ and located in the proximal colon. The carcinomas were pre-selected according to MSI-status and 27/52 (52\%) were MSI-positive.

\section{DNA promoter methylation in normal mucosa, adenomas, and carcinomas}

The results of the MSP analyses of all samples and each gene are summarized in Figure 2, Table 1, and Additional file 5 . The mean number of genes methylated per sample was 0.4 for the N1 group, 1.2 for N2, 2.2 for adenomas, and 3.9 for carcinomas, and was significantly different among the groups using Kruskal-Wallis test; $P<0.0001$ (mean rank N1, 10.2; N2, 17.3; adenomas, 23.1; and carcinomas, 31.4). Overall, $6 / 21(29 \%)$ of the N1 samples, $9 / 18(50 \%)$ of the N2 samples, 52/63 (83\%) of the adenomas, and 48/52 (92\%) of the carcinomas, were methylated in one or more of the eleven analyzed genes.

Statistically significant differences in methylation frequencies among sample groups were also evident at the single gene level. ADAMTS1, CDKN2A, CRABP1, MLH1, NR3C1, RUNX3, and SCGB3A1 showed increasing methylation frequencies from adenomas to carcinomas, while HOXA9, MAL, and MGMT displayed overall equal methylation frequencies in all tumor subgroups. PTEN was unmethylated in carcinomas, and was thus not investigated in adenomas or included in the figures, tables (except Additional file 4) or statistics.

The more frequent promoter hypermethylation found among N2 samples compared with N1 samples was apparent both for the total number of methylated genes, and at the individual gene level $(M G M T, P=0.055)$. The reliability of our MSP scorings was tested by quantitative MSP analysis of one example gene performed in a blinded manner in another lab. The results were in perfect concordance [see Additional file 6].

No difference was seen in methylation frequencies between N2 samples with corresponding MSI-positive carcinomas $(\mathrm{n}=6)$ and those with corresponding MSS carcinomas $(\mathrm{n}=12)$.

Overall, gene methylation frequencies were higher among MSI than among MSS carcinomas, and were statistically significant for CRABP1, MLH1, NR3C1, RUNX3, and SCGB3A1 $(P \leq 0.0001, P \leq 0.0001, P=0.001, P \leq 0.0001$, and $P=0.03$, respectively). Methylation of these genes

Table I: Gene promoter methylation and microsatellite instability

\begin{tabular}{|c|c|c|c|c|c|c|c|c|c|c|c|c|c|c|c|c|c|c|c|c|}
\hline & \multicolumn{2}{|c|}{ ADAMTSI } & \multicolumn{2}{|c|}{ CDKN2A } & \multicolumn{2}{|c|}{ CRABP I } & \multicolumn{2}{|c|}{ HOXA9 } & \multicolumn{2}{|c|}{ MAL } & \multicolumn{2}{|c|}{ MGMT } & \multicolumn{2}{|c|}{ MLHI } & \multicolumn{2}{|c|}{ NR3Cl } & \multicolumn{2}{|c|}{ RUNX3 } & \multicolumn{2}{|c|}{ SCGB3AI } \\
\hline & $M$ & $\mathbf{u}$ & $\mathbf{M}$ & $\mathbf{u}$ & $\mathbf{M}$ & $\mathbf{U}$ & $M$ & $\mathbf{U}$ & $\mathbf{M}$ & $\mathbf{U}$ & $\mathbf{M}$ & $\mathbf{U}$ & $\mathbf{M}$ & $\mathbf{U}$ & $\mathbf{M}$ & $\mathbf{U}$ & $M$ & $\mathbf{u}$ & $M$ & $\mathbf{u}$ \\
\hline \multicolumn{21}{|l|}{ Sample type } \\
\hline $\mathrm{NI}$ & 0 & 21 & 0 & 21 & 0 & 21 & 4 & 17 & I & 20 & 2 & 19 & 0 & 21 & 0 & 21 & 0 & I & I & 20 \\
\hline N2 & I & 17 & 2 & 16 & 0 & 18 & 7 & 11 & 2 & 16 & 7 & 10 & I & 17 & 0 & 18 & 0 & i & I & 17 \\
\hline Adenoma & 23 & 40 & 10 & 53 & 7 & 53 & 22 & 40 & 45 & 18 & 23 & 39 & 0 & 63 & 2 & 61 & 4 & 4 & 4 & 59 \\
\hline Carcinomas & 36 & 15 & 17 & 35 & 25 & 25 & 12 & 38 & 41 & 9 & 21 & 31 & 11 & 41 & 13 & 37 & 16 & 9 & 9 & 40 \\
\hline \multicolumn{21}{|l|}{ MSI status } \\
\hline \multicolumn{21}{|l|}{ Carcinomas } \\
\hline MSI & 19 & 8 & 10 & 17 & 22 & 5 & 7 & 20 & 21 & 6 & II & 16 & II & 16 & 12 & 15 & 16 & 8 & 8 & 18 \\
\hline MSS & 17 & 7 & 7 & 18 & 3 & 20 & 5 & 18 & 20 & 2 & 10 & 15 & 0 & 25 & I & 22 & 0 & I & 1 & 22 \\
\hline$P$ value & \multicolumn{2}{|c|}{ NS } & \multicolumn{2}{|c|}{ NS } & \multicolumn{2}{|c|}{$<0.0001$} & \multicolumn{2}{|c|}{ NS } & \multicolumn{2}{|c|}{ NS } & \multicolumn{2}{|c|}{ NS } & \multicolumn{2}{|c|}{$<0.0001$} & \multicolumn{2}{|c|}{0.001} & \multicolumn{2}{|c|}{$<0.0001$} & \multicolumn{2}{|c|}{0.026} \\
\hline
\end{tabular}

Abbreviations: $M$, methylated samples; $U$, unmethylated samples; NS, not significant; $N I$ : non-cancerous normal samples; $N 2$ : normal samples from cancer patients. MSI status data is listed for the individual polyp. In some cases a patient may have several polyps. 


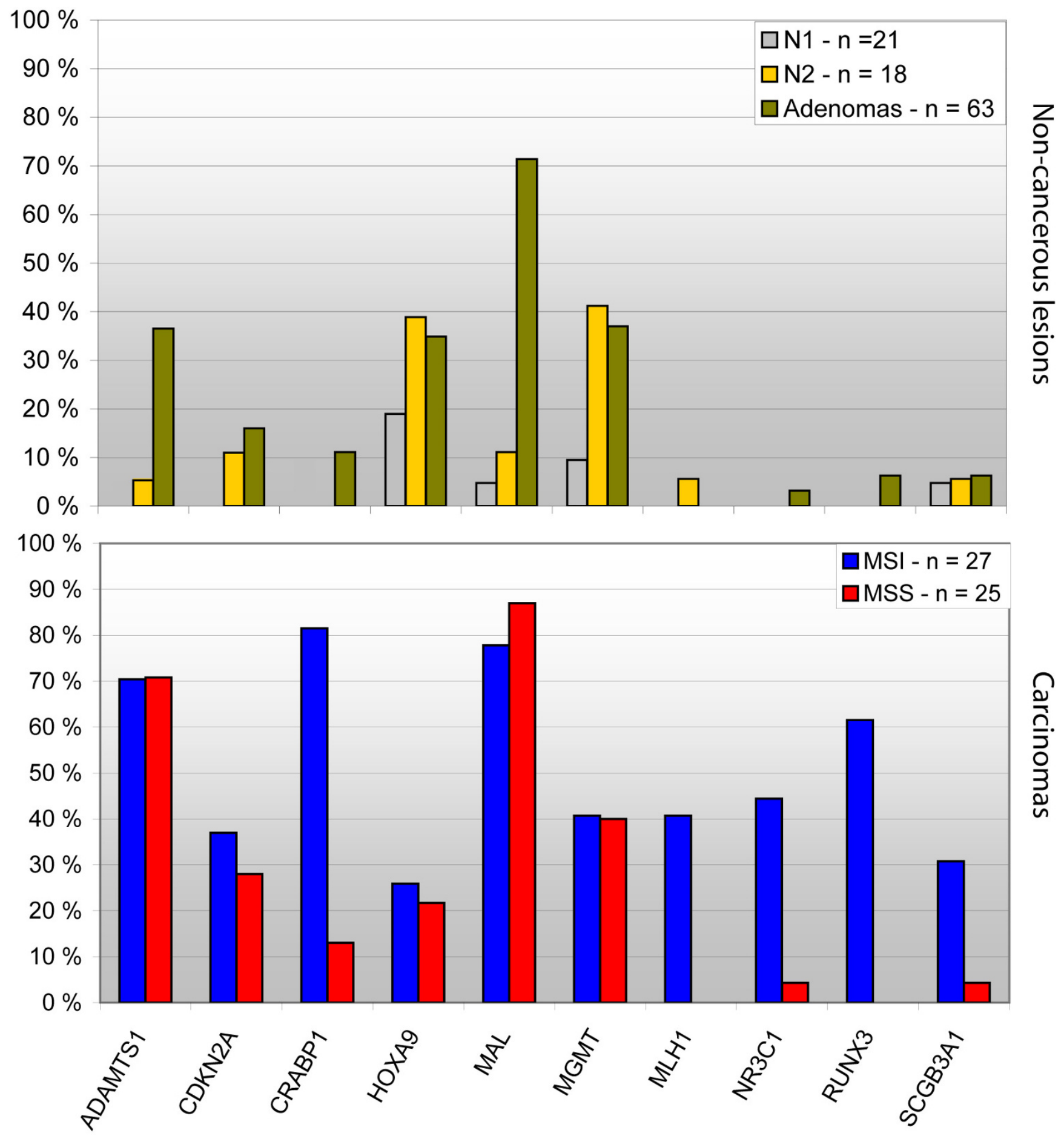

Figure 2

Methylation profiles of normal mucosa, adenomas, and carcinomas. Eleven genes were analyzed by MSP. Upper panel: non-cancerous lesions; lower panel: carcinomas stratified according to MSI-status. X-axis, the analyzed genes; $Y$-axis, the percentage of methylated samples. NI: normal colon samples from cancer-free individuals; N2: normal colon samples from cancer patients; MSI: microsatellite instability; MSS: microsatellite stability. 
showed a strong association to proximal carcinoma location, demonstrating the close connection between high methylation levels, proximal location and MSI $(P$ $\leq 0.0001, P \leq 0.0001, P \leq 0.001, P=0.001$, and $P=0.04$, respectively). Association to site was also seen for HOXA9 in $\mathrm{N} 1$ samples $(P=0.04)$. HOXA9 was also more frequently methylated among non-cancerous normal mucosa $(n=20)$ from older patients compared to younger patients, indicating age-specific methylation $(P=0.025)$. However, this was not confirmed among the larger group of carcinomas $(n=52)$.

\section{Interdependence among hypermethylated genes}

From bivariate correlation analysis [see Additional file 7], methylation of $M L H 1$ was correlated with methylation of CRABP1 (correlation coefficient $0.51 ; P=5 \times 10^{-11}$ ), NR3C1 (correlation coefficient $0.72 ; P=1 \times 10^{-25}$ ) and RUNX3 (correlation coefficient $0.57 ; P=6 \times 10^{-14}$ ). Methylation of RUNX3 itself was strongly correlated to methylation of both NR3C1 (correlation coefficient $0.75 ; P=5 \times$ $10^{-28}$ ) and CRABP1 (correlation coefficient $0.67 ; P=3 \times$ $10^{-20}$ ). Methylation of NR3C1 and CRABP1 was also correlated (correlation coefficient $0.59 ; P=4 \times 10^{-15}$ ), as well as ADAMTS1 and MAL (correlation coefficient $0.53 ; P=2$ $\left.\times 10^{-12}\right)$.

Hierarchical clustering of samples according to gene methylation status showed that MLH1 and NR3C1 were most closely related, followed by RUNX3 and CRABP1. In contrast, HOXA9 and MGMT displayed methylation patterns independent from each other and the other genes (Figure 3).

\section{Widespread methylation}

Several samples harbored simultaneous promoter methylation of two or more of the analyzed genes [see Additional file 8]. The distribution of methylated gene numbers per sample did not appear to be bimodal. Neither N1 nor N2 samples displayed methylation of five or more genes, here denoted widespread methylation. Seven of 63 (11\%) adenomas displayed widespread methylation, and these were by far larger in size ( mean $=19 \mathrm{~mm}$ ) than the remaining adenomas $($ mean $=10 \mathrm{~mm} ; P=0.013)$. In carcinomas, widespread methylation was seen more frequently in MSI $(16 / 27 ; 59 \%)$ than in MSS $(3 / 25 ; 12 \%)$ samples $(P=$ $0.001)$. All sixteen MSI samples with widespread methylation showed similar molecular profiles when DNA methylation status, TP53-, KRAS-, and BRAF-mutation status were considered, in line with a CIMP positive phenotype (Figure 4). The three MSS samples with widespread methylation included one tumor with TP53 mutation, one with both TP53 and KRAS mutation and one with BRAF mutation.

The distribution of the carcinomas combined with information regarding sex, age, MSI-status, and widespread

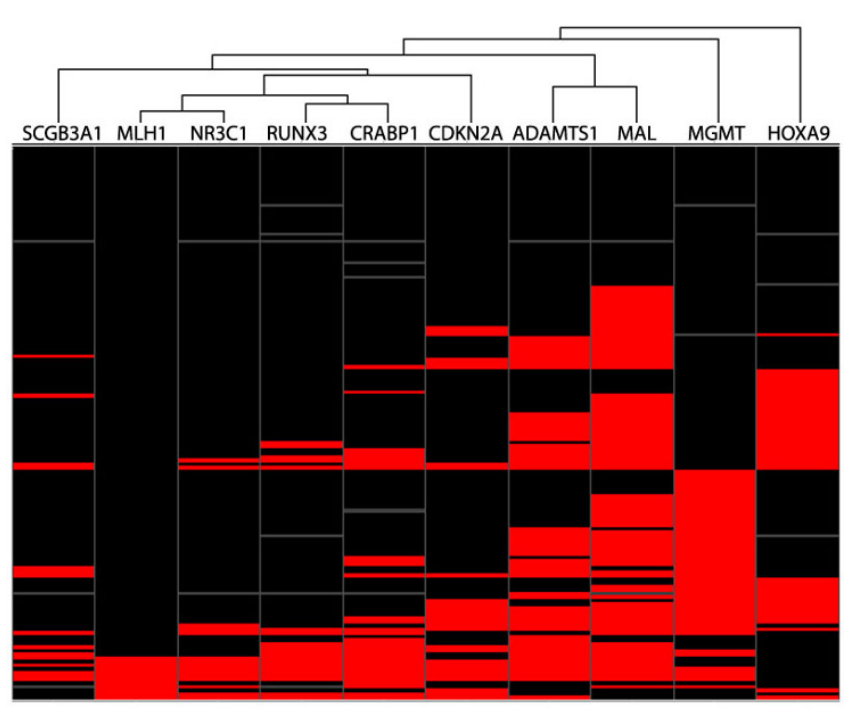

Figure 3

Methylation HeatMap. Hierarchical clustering reveals that methylation of $\mathrm{NR3CI}$ and RUNX3 are most closely related, followed by $M L H I$ and CRABPI. Methylation of MGMT and HOXA9 are most independent both from each other and from rest of the set. The genes are presented in columns, while the samples are presented in rows. Black, unmethylated; red, methylated; and grey, missing values.

methylation is illustrated in Figure 5. From the figure we see that widespread methylation is associated with proximal tumors derived from elderly women.

\section{Discussion}

We demonstrate in the present study aberrant promoter methylation of several genes, at variable frequencies, in the stepwise development of colorectal tumors.

An association between hypermethylation and lack of expression has previously been shown for all genes analyzed in the present study. [8-10,25-28] Although multiple genes are methylated in a cancer, only some are functionally involved in tumorigenesis, [29-31] whereas others with unknown functional contribution still may serve as good biomarkers from a diagnostic perspective.

\section{Comparing methylation profiles of normal mucosa, adenomas and carcinomas of the large bowel}

The identified methylation profiles of normal colorectal tissues, adenomas, and carcinomas demonstrated a stepwise increase in $\mathrm{CpG}$ island promoter methylation towards malignancy, indicating that their inactivation plays a role in the progression of the tumor. This was evident both for widespread methylation and at the single gene level (increasing frequencies of methylation from benign to malignant stages) with the exception of HOXA9, MAL, and MGMT. The lack of increase in methylation frequencies between non-malignant adenomas and 

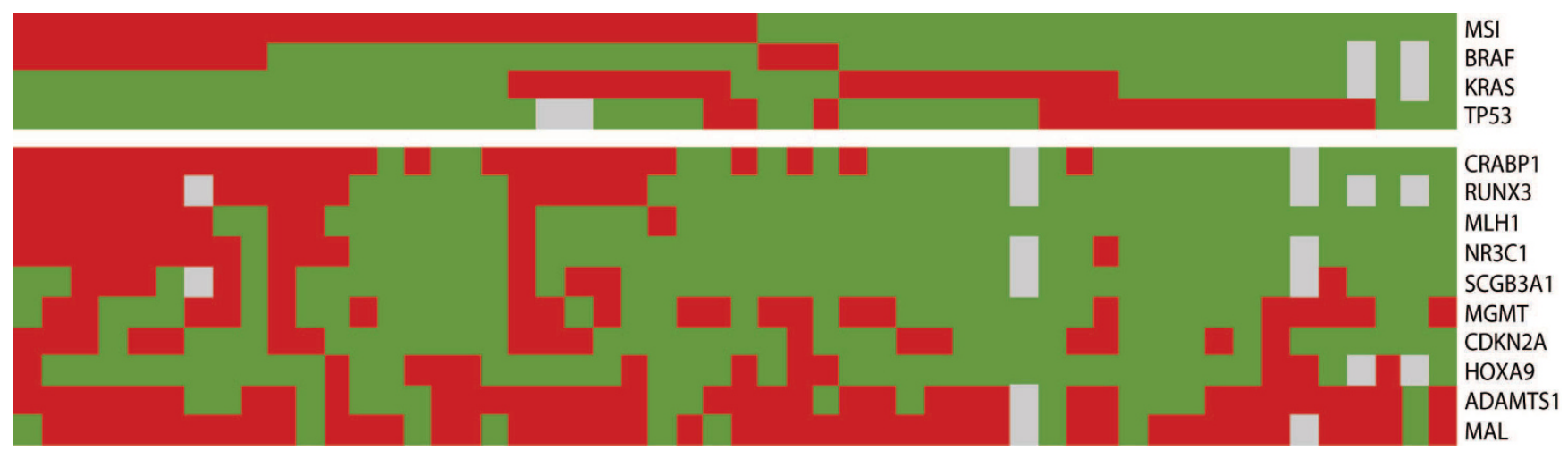

\section{Figure 4}

Genetic and epigenetic changes in colorectal carcinomas with known microsatellite status. The results are visualized according to genetic (top part of the figure) and epigenetic changes (lower part of the figure). The results are organized according to MSI, followed by BRAF-, KRAS-, TP53- and methylation-status of the MSI associated genes.

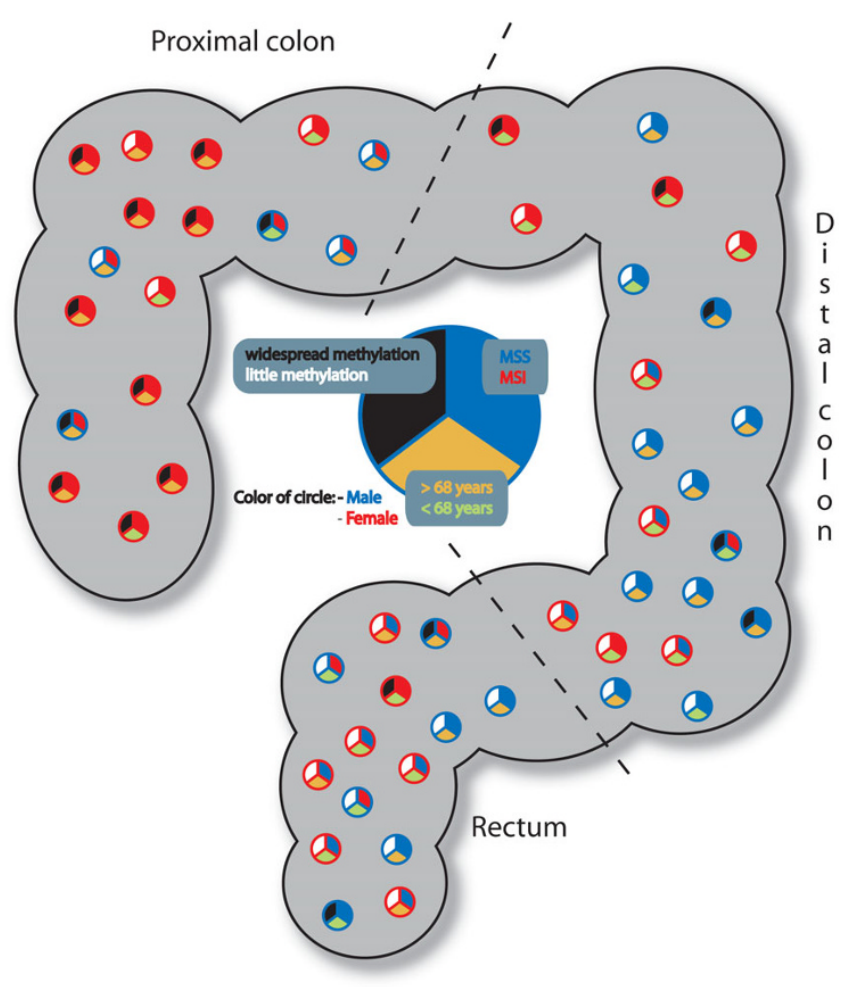

\section{Figure 5}

Distribution of colorectal carcinomas according to site associates with sex, age, MSI-status and methylation frequencies. The circles indicate 52 carcinomas placed according to site, the red circle $=$ female, the blue $=$ male . Top right section of the circle: blue $=$ MSS, red $=$ MSI. The lowest section: green $=$ patient $<68$ years of age, yellow $=$ patient $\geq 68$ years. Widespread methylation is given in the top left section: white $=$ methylation in $<5$ genes, black $=$ widespread methylation $\geq 5$ genes. carcinomas for these three genes may suggest that they are more important in the initiation of cancer, rather than in progression. These genes in addition to ADAMTS1 were also hypermethylated in comparable frequencies among MSS and MSI carcinomas. These observations, and the fact that the separation of the MSI- and MSS-pathway is thought to occur early in colorectal tumorigenesis suggest that alterations of the four genes represent early events. ADAMTS1 is believed to be an inhibitor of both angiogenesis and endothelial proliferation,[32] features commonly activated in cancer, as a tumor must turn on angiogenesis in order to grow larger than 1-2 $\mathrm{mm}^{3}[33]$. Members of the HOX gene family are shown to be commonly altered in several cancers, and to the best of our knowledge, this is the first report of HOXA9 methylation in colorectal neoplasms. HOXA9 methylation has received increasing interest in recent time as it is included in the HOXA-cluster which harbors methylation over a larger area than just a single promoter, indicating that methylation may mimic genetic micro-deletions and turn off a cluster of genes rather than just one at the time, i.e. yet another example of long range epigenetic silencing. [34-36]. MAL is involved in T-cell differentiation, especially in the late or intermediate stages.[37] It is also involved in polarization of epithelial cells caused by apical transport of lipids and proteins. Loss of cell polarity is often seen in neoplastic transformation.[38] For MGMT the early involvement is further supported by the fact that promoter methylation has previously been identified in aberrant crypt foci.[39]

Our data do not suggest that any of the markers included here were methylated in an age dependent manner. Of the 11 analyzed genes, six were unmethylated in all normal samples from non-affected individuals, excluding them as age-specific methylation targets. For two genes (SCGB3A1 and $M A L$ ) only one of 21 samples was methylated. 
Although the sample in question was from an older individual (75 years), the resulting overall methylation frequency was only $5 \%$. This is in strong contrast to the frequent reported age-specific methylation of the N33 gene, which shows approximately $46 \%$ methylation among normal samples in general and 58\% methylation in normal samples from individuals over 60 years.[40]HOXA9 is the only gene in the present study harboring "frequent" promoter methylation in normal samples (19\% overall, and $43 \%$ for individuals of 60 years or older). Binary regression analysis resulted in a significant $P$ value, however, when using the same statistical analysis in the tumor sample series age dependence could not be confirmed. Both technical and biological aspects influence the interpretation of DNA promoter methylation analyses.

The importance of primer design is emphasized in the PTEN assay. Promoter hypermethylation of PTEN has been frequently reported in various tumor types, including CRC. [16-19] However, the majority of MSP primer sets used have failed to discriminate between PTEN and its frequently methylated pseudogene, leading to a high rate of false positives.[20] In the present study, we used MSP primers specifically designed to amplify the proteinencoding PTEN gene, [21] and showed that PTEN was not subject to promoter hypermethylation in colorectal carcinomas. A novel study confirms that methylation of PTEN is an unusual event in colorectal cancer as a whole.[22]

\section{Interdependence among hypermethylated genes and widespread methylation}

The hierarchical clustering analysis of gene promoter methylation status in normal, benign, and malignant samples confirmed that the distribution of HOXA9 and MGMT methylation frequencies across sample groups differed from the other genes. Overall, methylation of $N R 3 C 1$ and RUNX3 had the highest correlation (Figure 3 and Additional file 7), in addition to $M L H 1$, which was also closely related to NR3C1 and RUNX3. Furthermore, the present study confirmed that hypermethylation of MLH1 was characteristic of right-sided sporadic colon tumors with MSI.[41] The lack of MLH1 hypermethylation in adenomas analyzed in the present study supports the theory that CIMP and MSI-tumors arise from sessile serrated polyps rather than from adenomas.[42]NR3C1, RUNX3, CRABP1, and SCGB3A1 were also shown to have the same characteristics as $M L H 1$, supporting the hypothesis that DNA methylation plays a more prominent role in proximal than in distal carcinogenesis. CRABP1, MLH1, NR3C1, and RUNX3 have recently been shown to belong to a panel of epigenetically regulated genes which best discriminate between CIMP-positive and CIMP-negative tumors, a phenotype strongly related with MSI status.[43]

We found that the MSI positive samples with V600E BRAF mutations were accompanied by promoter hypermethylation of several genes, in agreement with the CIMP phenotype (Figure 4). Furthermore, we also confirmed that MSS tumors with TP53 mutations had less overall methylation, and thus in agreement with a CIMP negative phenotype. KRAS mutations were evenly distributed between MSI and MSS samples but seemingly the KRAS/MSI samples had more methylation than KRAS/MSS samples. Interestingly, three MSS samples had BRAF mutations, and all differed from the V600E mutation found among the MSI tumors.

\section{Methylation markers suitable for early tumor detection}

For genes previously analyzed for promoter methylation in normal colon samples, our results are within the expected range (CDKN2A, 0-33\% (range of samples 9100 , total methylation frequency 4\%) [44-57]; MGMT, 0-39\% (range of samples 12-220, total methylation frequency 7\%) $[14,15,44,49,50,53,56-61]$; and MLH1, 0$50 \%$ (range of samples 8-100, total methylation frequency $\quad \sim 5 \%))$.[44,46,49,50,52,53,55-57,6267]SCGB3A1 and RUNX3 have previously been analyzed in only one study, and both were unmethylated in 57 normal samples.[48] The study showing the highest methylation frequency of CDKN2A and MLH1 were biased towards normal samples taken distant from MSI- and CIMP-positive tumors, [46] thus a higher degree of methylation might be expected.

A suitable, highly specific, biomarker should be unmethylated in normal mucosa from healthy individuals and frequently methylated in carcinomas, and possibly also in benign lesions. To date, only few such markers have been identified, $[10,68,69]$ and one of the most suitable ones, Vimentin, is non-expressed in a normal, healthy, colon. [69] The fact that an important biomarker is nonexpressed in normal tissue supports the choice of a low threshold for methylation positive early lesions, applied in the present search for early onset biomarkers. Hypermethylation of genes such as ADAMTS1 and MAL are also suitable biomarkers for early detection, as they are infrequently methylated in normal mucosa taken from individuals without cancer ( $0 \%$ and $5 \%$, respectively), but highly methylated in malignant lesions (71\% and $82 \%$, respectively)[9,13]. In addition, both are frequently hypermethylated among the adenomas (37\% and $71 \%$, respectively) independent of size. Of course, sufficient sensitivity and specificity of these hypermethylation markers must be shown in feces or blood samples for the purpose of non-invasive testing. It should be note that this 
is an obstacle yet to be overcomed by suggested markers in existing non-invasive tests.

It has been speculated that methylation of specific genes, such as MGMT, may yield a so-called "field effect", providing favorable conditions for further alterations which eventually might lead to tumor formation. $[58,70]$ The initial steps in tumorigenesis might be due to an epigenetic disruption of a progenitor/stem cell which may be followed by genetic mutations of gatekeeper genes, and the subsequent acquisition of other genetic and epigenetic alterations.[71] This model provides a possible explanation of why we see relatively high methylation frequencies for genes such as MGMT, and HOXA9 in normal samples taken from cancer patients.

Summarized, this study has shown that gene-specific promoter hypermethylation is an early event in colorectal tumorigenesis, exemplified by hypermethylation of MGMT in adenomas and normal mucosa from cancer patients, and by the high frequency of ADAMTS1 and $M A L$ methylation in polyps irrespective of size. These markers are suitable as part of a panel aiming at detecting early colorectal lesions, and possibly a field effect in a "labile" colon. In general, we saw that aberrant CpG island hypermethylation increased with malignancy. Finally, methylation of CRABP1, MLH1, NR3C1, RUNX3, and SCGB3A1 were identifiers of MSI carcinomas.

\section{Competing interests}

The authors declare that they have no competing interests.

\section{Authors' contributions}

All authors have read and approved the final version of the manuscript. TA was main responsible for the laboratory analyses, performed statistical analyses, made all figures and drafted the manuscript. GEL participated in the study design, in experimental analyses and in the preparation of the manuscript. VLC performed the quantitative methylation specific PCR analysis. GIM collected the cancer series and provided the clinicopathological information. MV participated in the screening study from which we received adenomas and patient information. GSH was responsible for the screening study from which we received adenomas and patient information. TOR collected and provided normal mucosa from non-cancerous individuals, the carcinoma series and participated in scientific discussions. RIS contributed to the statistical analyses and in scientific discussions. ETE participated in the screening study from which we received adenomas and patient information as well as in study design and scientific discussions. RAL conceived the study, participated in the evaluation of the results and in manuscript preparation.

\section{Additional material}

\section{Additional file 1}

Supplementary information. Methodological details which are not crucial for the understanding of the work, as well as Additional figure legends.

Click here for file

[http://www.biomedcentral.com/content/supplementary/14764598-7-94-S1.doc]

\section{Additional file 2}

Titration of methylated DNA template illustrates the scoring thresholds for the methylation-specific polymerase chain reaction. Determination of scoring thresholds is visualized by a titration series of the RUNX3 gene.

Click here for file

[http://www.biomedcentral.com/content/supplementary/14764598-7-94-S2.jpeg]

\section{Additional file 3}

PCR primers used for methylation-specific PCR and microsatellite instability analyses. Information on primers and PCR details. Click here for file

[http://www.biomedcentral.com/content/supplementary/14764598-7-94-S3.xls]

\section{Additional file 4}

Genetic and epigenetic raw data. Raw data from all analyses are listed for each tumor included.

Click here for file

[http://www.biomedcentral.com/content/supplementary/14764598-7-94-S4.xls]

\section{Additional file 5}

Summarized methylation raw data. Methylation frequencies are presented for each of the eleven analyzed genes in the 4 different sample types according to what methylation level they exhibited (strong, weak or no methylation).

Click here for file

[http://www.biomedcentral.com/content/supplementary/14764598-7-94-S5.xls]

\section{Additional file 6}

Comparison between MSP and quantitative MSP in normal mucosa samples. Hypermethylation of was analyzed with both non-quantitativeand quantitative MSP. Here the results from each method are presented. Click here for file

[http://www.biomedcentral.com/content/supplementary/14764598-7-94-S6.jpeg]

\section{Additional file 7}

Correlation between methylated genes. A correlation table including all analyzed for promoter hypermethylation shown that genes commonly methylated in MSI tumors are highly correlated.

Click here for file

[http://www.biomedcentral.com/content/supplementary/14764598-7-94-S7.xls] 


\section{Additional file 8}

Widespread methylation among normal colorectal samples, adenomas, and carcinomas. A histogram showing the total number of methylated genes per sample in non-cancerous normal mucosa, normal mucosa taken in distance from a primary tumor, adenomas, and carcinomas stratified according to MSI status.

Click here for file

[http://www.biomedcentral.com/content/supplementary/14764598-7-94-S8.jpeg]

\section{Acknowledgements}

This study was funded by grants from the Norwegian Research Council (163962/V50 and 161448/V40, RAL), the latter supporting TA as a PhD student. Funding was also received from the Norwegian Cancer Society (A95068, RAL) supporting GEL as post doctoral fellow.

\section{References}

I. Ponz DL, Di Gregorio C: Pathology of colorectal cancer. Dig Liver Dis 200I, 33:372-388.

2. Grady WM, Markowitz SD: Genetic and epigenetic alterations in colon cancer. Annu Rev Genomics Hum Genet 2002, 3:10I-28. Epub@2002 Apr 15.:101-128.

3. Toyota M, Ahuja N, Ohe-Toyota M, Herman JG, Baylin SB, Issa JP: CpG island methylator phenotype in colorectal cancer. Proc Natl Acad Sci USA 1999, 96:868I-8686.

4. Shen L, Toyota M, Kondo Y, Lin E, Zhang L, Guo Y, Hernandez NS, Chen X, Ahmed S, Konishi K, et al:: Integrated genetic and epigenetic analysis identifies three different subclasses of colon cancer. Proc Natl Acad Sci USA 2007, 104: 18654-18659.

5. Meling GI, Lothe RA, Børresen AL, Hauge S, Graue C, Clausen OP, Rognum TO: Genetic alterations within the retinoblastoma locus in colorectal carcinomas. Relation to DNA ploidy pattern studied by flow cytometric analysis. Br J Cancer 1991, 64:475-480.

6. Thiis-Evensen E, Hoff GS, Sauar J, Langmark F, Majak BM, Vatn MH: Population-based surveillance by colonoscopy: effect on the incidence of colorectal cancer. Telemark Polyp Study I. Scand J Gastroenterol 1999, 34:414-420.

7. Frommer M, McDonald LE, Millar DS, Collis CM, Watt F, Grigg GW, Molloy PL, Paul CL: A genomic sequencing protocol that yields a positive display of 5-methylcytosine residues in individual DNA strands. Proc Natl Acad Sci USA 1992, 89: |827-I83|.

8. Herman JG, Graff JR, Myöhänen S, Nelkin BD, Baylin SB: Methylation-specific PCR: a novel PCR assay for methylation status of CpG islands. Proc Natl Acad Sci USA 1996, 93:9821-9826.

9. Lind GE, Kleivi K, Meling GI, Teixeira MR, Thiis-Evensen E, Rognum TO, Lothe RA: ADAMTSI, CRABPI, and NR3CI identified as epigenetically deregulated genes in colorectal tumorigenesis. Cell Oncol 2006, 28:259-272.

10. Lind GE, Ahlquist T, Lothe RA: DNA hypermethylation of MAL: a promising diagnostic biomarker for colorectal tumors. Gastroenterology 2007, 132:1631-1632.

II. Lind GE, Thorstensen L, Løvig T, Meling GI, Hamelin R, Rognum TO, Esteller M, Lothe RA: A CpG island hypermethylation profile of primary colorectal carcinomas and colon cancer cell lines. Mol Cancer 2004, 3:28.

12. Eads CA, Lord RV, Wickramasinghe K, Long TI, Kurumboor SK, Bernstein L, Peters JH, DeMeester SR, DeMeester TR, Skinner KA, et al.: Epigenetic patterns in the progression of esophageal adenocarcinoma. Cancer Res 2001, 61:3410-34I8.

13. Lind GE, Ahlquist T, Kolberg M, Berg M, Eknaes M, Alonso MA, Kallioniemi A, Meling Gl, Skotheim RI, Rognum TO, et al:: Hypermethylated MAL gene - a silent marker of early colon tumorigenesis. J Transl Med 2008, 6(13):13.

14. Nagasaka T, Goel A, Notohara K, Takahata T, Sasamoto H, Uchida T, Nishida N, Tanaka N, Boland CR, Matsubara N: Methylation pattern of the O6-methylguanine-DNA methyltransferase gene in colon during progressive colorectal tumorigenesis. Int J Cancer 2008, 122:2429-2436.

15. Bai AH, Tong JH, To KF, Chan MW, Man EP, Lo KW, Lee JF, Sung JJ, Leung WK: Promoter hypermethylation of tumor-related genes in the progression of colorectal neoplasia. Int J Cancer 2004, I I 2:846-853.

16. Kang YH, Lee HS, Kim WH: Promoter methylation and silencing of PTEN in gastric carcinoma. Lab Invest 2002, 82:285-29I.

17. Baeza N, Weller M, Yonekawa Y, Kleihues P, Ohgaki H: PTEN methylation and expression in glioblastomas. Acta Neuropathol (Berl) 2003, 106:479-485.

18. Khan S, Kumagai T, Vora J, Bose N, Sehgal I, Koeffler PH, Bose S: PTEN promoter is methylated in a proportion of invasive breast cancers. Int J Cancer 2004, I I 2:407-4IO.

19. Goel A, Arnold CN, Niedzwiecki D, Carethers JM, Dowell JM, Wasserman L, Compton C, Mayer RJ, Bertagnolli MM, Boland CR: Frequent inactivation of PTEN by promoter hypermethylation in microsatellite instability-high sporadic colorectal cancers. Cancer Res 2004, 64:3014-302I.

20. Zysman MA, Chapman WB, Bapat B: Considerations when analyzing the methylation status of PTEN tumor suppressor gene. Am J Pathol 2002, 160:795-800.

21. Garcia JM, Silva J, Pena C, Garcia V, Rodriguez R, Cruz MA, Cantos B, Provencio M, Espana P, Bonilla F: Promoter methylation of the PTEN gene is a common molecular change in breast cancer. Genes Chromosomes Cancer 2004, 41: I 17-124.

22. Goel A, Nagasaka T, Arnold CN, Inoue T, Hamilton C, Niedzwiecki D, Compton C, Mayer RJ, Goldberg R, Bertagnolli MM, et al.: The CpG island methylator phenotype and chromosomal instability are inversely correlated in sporadic colorectal cancer. Gastroenterology 2007, I32:127-138.

23. Ahlquist T, Bottillo I, Danielsen SA, Meling GI, Rognum TO, Lind GE, Dallapiccola $B$, Lothe RA: RAS signaling in colorectal carcinomas through alteration of RAS, RAF, NFI, and/or RASSFIA. Neoplasia 2008, 10:680-6. 2.

24. Diep CB, Thorstensen L, Meling GI, Skovlund E, Rognum TO, Lothe RA: Genetic tumor markers with prognostic impact in Dukes' stages B and C colorectal cancer patients. J Clin Oncol 2003, $21: 820-829$.

25. Esteller M, Hamilton SR, Burger PC, Baylin SB, Herman JG: Inactivation of the DNA repair gene O6-methylguanine-DNA methyltransferase by promoter hypermethylation is a common event in primary human neoplasia. Cancer Res 1999, 59:793-797.

26. Krop IE, Sgroi D, Porter DA, Lunetta KL, LeVangie R, Seth P, Kaelin $C M$, Rhei E, Bosenberg M, Schnitt S, et al.: HIN-I, a putative cytokine highly expressed in normal but not cancerous mammary epithelial cells. Proc Natl Acad Sci USA 200I, 98:9796-980I.

27. Alaminos M, Davalos V, Cheung NK, Gerald WL, Esteller M: Clustering of gene hypermethylation associated with clinical risk groups in neuroblastoma. J Natl Cancer Inst 2004, 96: I 208- 1219.

28. Goel A, Arnold CN, Tassone P, Chang DK, Niedzwiecki D, Dowell JM, Wasserman L, Compton C, Mayer RJ, Bertagnolli MM, et al.: Epigenetic inactivation of RUNX3 in microsatellite unstable sporadic colon cancers. Int I Cancer 2004, I I 2:754-759.

29. Costello JF, Fruhwald MC, Smiraglia DJ, Rush LJ, Robertson GP, Gao $X$, Wright FA, Feramisco JD, Peltomaki P, Lang JC, et al.: Aberrant CpG-island methylation has non-random and tumour-typespecific patterns. Nat Genet 2000, 24: 132-138.

30. Hayashi H, Nagae G, Tsutsumi S, Kaneshiro K, Kozaki T, Kaneda A, Sugisaki $H$, Aburatani $H$ : High-resolution mapping of DNA methylation in human genome using oligonucleotide tiling array. Hum Genet 2007, I 20:701-7II.

3I. Schuebel KE, Chen W, Cope L, Glockner SC, Suzuki H, Yi JM, Chan TA, van Neste L, van Criekinge W, van den Bosch S, et al: Comparing the DNA hypermethylome with gene mutations in human colorectal cancer. PLoS Genet 2007, 3: 1709-1723.

32. Kuno K, Bannai K, Hakozaki M, Matsushima K, Hirose K: The carboxyl-terminal half region of ADAMTS-I suppresses both tumorigenicity and experimental tumor metastatic potential. Biochem Biophys Res Commun 2004, 3 1 9: I 327-1333.

33. Folkman J: Angiogenesis. Annu Rev Med 2006, 57:I-I8.

34. Novak P, Jensen T, Oshiro MM, Wozniak RJ, Nouzova M, Watts GS, Klimecki WT, Kim C, Futscher BW: Epigenetic inactivation of 
the HOXA gene cluster in breast cancer. Cancer Res 2006, 66:10664-10670.

35. Strathdee G, Holyoake TL, Sim A, Parker A, Oscier DG, Melo JV, Meyer S, Eden T, Dickinson AM, Mountford JC, et al:: Inactivation of HOXA genes by hypermethylation in myeloid and lymphoid malignancy is frequent and associated with poor prognosis. Clin Cancer Res 2007, I 3:5048-5055.

36. Frigola J, Song J, Stirzaker C, Hinshelwood RA, Peinado MA, Clark SJ: Epigenetic remodeling in colorectal cancer results in coordinate gene suppression across an entire chromosome band. Nat Genet 2006, 38:540-549.

37. Alonso MA, Weissman SM: cDNA cloning and sequence of MAL, a hydrophobic protein associated with human T-cell differentiation. Proc Natl Acad Sci USA 1987, 84:1997-200I.

38. Marazuela M, Alonso MA: Expression of MAL and MAL2, two elements of the protein machinery for raft-mediated transport, in normal and neoplastic human tissue. Histol Histopathol 2004, 19:925-933.

39. Chan AO, Broaddus RR, Houlihan PS, Issa JP, Hamilton SR, Rashid A: CpG island methylation in aberrant crypt foci of the colorectum. Am J Pathol 2002, 160:1823-1830.

40. Ahuja N, Li Q, Mohan AL, Baylin SB, Issa JP: Aging and DNA methylation in colorectal mucosa and cancer. Cancer Res 1998 , 58:5489-5494.

4I. Jass JR: Colorectal cancer: a multipathway disease. Crit Rev Oncog 2006, I 2:273-287.

42. Jass JR: Molecular heterogeneity of colorectal cancer: Implications for cancer control. Surg Oncol 2007, I6(SuppI I):S7-9. Epub;\%2007 Nov 26.:S7-S9.

43. Weisenberger DJ, Siegmund KD, Campan M, Young J, Long TI, Faasse MA, Kang GH, Widschwendter M, Weener D, Buchanan D, et al:: CpG island methylator phenotype underlies sporadic microsatellite instability and is tightly associated with BRAF mutation in colorectal cancer. Nat Genet 2006, 38:787-793.

44. Lee S, Hwang KS, Lee HJ, Kim JS, Kang GH: Aberrant CpG island hypermethylation of multiple genes in colorectal neoplasia. Lab Invest 2004, 84:884-893.

45. Ebert MP, Mooney SH, Tonnes-Priddy L, Lograsso J, Hoffmann J, Chen J, Rocken C, Schulz HU, Malfertheiner P, Lofton-Day C: Hypermethylation of the TPEF/HPPI gene in primary and metastatic colorectal cancers. Neoplasia 2005, 7:77I-778.

46. Kawakami K, Ruszkiewicz A, Bennett G, Moore J, Grieu F, Watanabe $\mathrm{G}$, lacopetta $\mathrm{B}$ : DNA hypermethylation in the normal colonic mucosa of patients with colorectal cancer. BrJ Cancer 2006, 94:593-598.

47. Minoo P, Baker K, Goswami R, Chong G, Foulkes W, Ruszkiewicz A, Barker M, Buchanan D, Young J, Jass JR: Extensive DNA methylation in normal colorectal mucosa in hyperplastic polyposis. Gut 2006, 55: | $467-1474$.

48. Takahashi T, Shigematsu H, Shivapurkar N, Reddy J, Zheng Y, Feng Z, Suzuki M, Nomura M, Augustus M, Yin J, et al:: Aberrant promoter methylation of multiple genes during multistep pathogenesis of colorectal cancers. Int I Cancer 2006, I I 8:924-93 I

49. Derks S, Postma C, Moerkerk PT, Bosch SM van den, Carvalho B, Hermsen MA, Giaretti W, Herman JG, Weijenberg MP, de Bruine AP, et al.: Promoter methylation precedes chromosomal alterations in colorectal cancer development. Cell Oncol 2006, 28:247-257.

50. Ye C, Shrubsole MJ, Cai Q, Ness R, Grady WM, Smalley W, Cai H, Washington K, Zheng W: Promoter methylation status of the MGMT, hMLHI, and CDKN2A/pl 6 genes in non-neoplastic mucosa of patients with and without colorectal adenomas. Oncol Rep 2006, 16:429-435.

5I. Lee M, Sup HW, Kyoung KO, Hee SS, Sun CM, Lee SN, Koo H: Prognostic value of p I 6(INK4a) and p I 4(ARF) gene hypermethylation in human colon cancer. Pathol Res Pract 2006, 202:4 I5-424.

52. Park SJ, Rashid A, Lee JH, Kim SG, Hamilton SR, Wu TT: Frequent CpG island methylation in serrated adenomas of the colorectum. Am J Pathol 2003, 162:815-822.

53. Kim HC, Lee HJ, Roh SA, Kim JS, Yu CS, Kim JC: CpG island methylation in familial colorectal cancer patients not fulfilling the Amsterdam criteria. J Korean Med Sci 2008, 23:270-277.

54. Ishiguro A, Takahata T, Saito M, Yoshiya G, Tamura Y, Sasaki M, Munakata A: Influence of methylated pI5 and pl6 genes on clinicopathological features in colorectal cancer. j Gastroenterol Hepatol 2006, 21:1334-1339.
55. Deng G, Kakar S, Tanaka H, Matsuzaki K, Miura S, Sleisenger MH, Kim YS: Proximal and distal colorectal cancers show distinct gene-specific methylation profiles and clinical and molecular characteristics. Eur J Cancer 2008, 44: I 290- I30|

56. Belshaw NJ, Elliott GO, Foxall RJ, Dainty JR, Pal N, Coupe A, Garg D, Bradburn DM, Mathers JC, Johnson IT: Profiling CpG island field methylation in both morphologically normal and neoplastic human colonic mucosa. Br J Cancer 2008, 99: I36-142.

57. Petko Z, Ghiassi M, Shuber A, Gorham J, Smalley W, Washington MK, Schultenover S, Gautam S, Markowitz SD, Grady WM: Aberrantly Methylated CDKN2A, MGMT, and MLHI in Colon Polyps and in Fecal DNA from Patients with Colorectal Polyps. Clin Cancer Res 2005, I I:1203-1209.

58. Shen L, Kondo Y, Rosner GL, Xiao L, Hernandez NS, Vilaythong J, Houlihan PS, Krouse RS, Prasad AR, Einspahr JG, et al:: MGMT promoter methylation and field defect in sporadic colorectal cancer. J Natl Cancer Inst 2005, 97: I 330- I 338.

59. Cheng YW, Shawber C, Notterman D, Paty P, Barany F: Multiplexed profiling of candidate genes for CpG island methylation status using a flexible PCR/LDR/Universal Array assay. Genome Res 2006, 16:282-289.

60. Huang ZH, Li LH, Yang F, Wang JF: Detection of aberrant methylation in fecal DNA as a molecular screening tool for colorectal cancer and precancerous lesions. World J Gastroenterol 2007, 13:950-954.

6I. Menigatti M, Pedroni M, Verrone AM, Borghi F, Scarselli A, Benatti P, Losi L, Di GC, Schar P, Marra G, et al.: O6-methylguanine-DNA methyltransferase promoter hypermethylation in colorectal carcinogenesis. Oncol Rep 2007, I7: | 142I-I 427.

62. Koinuma K, Kaneda R, Toyota M, Yamashita Y, Takada S, Choi YL, Wada T, Okada M, Konishi $F$, Nagai $H$, et al:: Screening for genomic fragments that are methylated specifically in colorectal carcinoma with a methylated MLHI promoter. Carcinogenesis 2005, 26:2078-2085.

63. Nuovo GJ, Nakagawa H, Sotamaa K, Chapelle ADL: Hypermethylation of the MLHI promoter with concomitant absence of transcript and protein occurs in small patches of crypt cells in unaffected mucosa from sporadic colorectal carcinoma. Diagn Mol Pathol 2006, 15:17-23.

64. Ide T, Kitajima Y, Ohtaka K, Mitsuno M, Nakafusa Y, Miyazaki K: Expression of the $h M L H I$ gene is a possible predictor for the clinical response to 5-fluorouracil after a surgical resection in colorectal cancer. Oncol Rep 2008, 19:157I-1576.

65. Hitchins MP, Lin VA, Buckle A, Cheong K, Halani N, Ku S, Kwok CT, Packham D, Suter CM, Meagher A, et al.: Epigenetic inactivation of a cluster of genes flanking MLHI in microsatellite-unstable colorectal cancer. Cancer Res 2007, 67:9107-9116.

66. Leung WK, To KF, Man EP, Chan MW, Bai AH, Hui AJ, Chan FK, Sung $\mathrm{JJ}$ : Quantitative detection of promoter hypermethylation in multiple genes in the serum of patients with colorectal cancer. Am J Gastroenterol 2005, 100:2274-2279.

67. Xiong Z, Wu AH, Bender CM, Tsao JL, Blake C, Shibata D, Jones PA, Yu MC, Ross RK, Laird PW: Mismatch repair deficiency and CpG island hypermethylation in sporadic colon adenocarcinomas. Cancer Epidemiol Biomarkers Prev 200I, I 0:799-803.

68. Muller HM, Oberwalder M, Fiegl H, Morandell M, Goebel G, Zitt M, Muhlthaler M, Ofner D, Margreiter R, Widschwendter M: Methylation changes in faecal DNA: a marker for colorectal cancer screening? Lancet 2004, 363: | 283-1285.

69. Chen WD, Han ZJ, Skoletsky J, Olson J, Sah J, Myeroff L, Platzer P, Lu $S$, Dawson D, Willis J, et al.: Detection in fecal DNA of colon cancer-specific methylation of the nonexpressed vimentin gene. J Natl Cancer Inst 2005, 97: I I 24- I I 32.

70. Giovannucci E, Ogino S: DNA methylation, field effects, and colorectal cancer. J Natl Cancer Inst 2005, 97:1317-1319.

71. Feinberg AP, Ohlsson R, Henikoff S: The epigenetic progenitor origin of human cancer. Nat Rev Genet 2006, 7:21-33. 